\title{
Micelle-Mediated Extraction Prior to LC-UV for Preconcentration and Determination of Trace Amounts of Bisphenol A in Environmental Samples
}

\author{
Naghi Saadatjou, ${ }^{1}$ Shahab Shariati, ${ }^{2}$ and Mostafa Golshekan ${ }^{1}$ \\ ${ }^{1}$ Department of Chemistry, Faculty of Sciences, Semnan University, Semnan, Iran \\ ${ }^{2}$ Department of Chemistry, Faculty of Sciences, Rasht Branch, Islamic Azad University, Rasht, Iran \\ Correspondence should be addressed to Shahab Shariati; shariaty@iaurasht.ac.ir
}

Received 27 March 2013; Accepted 16 April 2013

Academic Editors: C. Desiderio, R. K. Jyothi, J. J. Santana Rodriguez, and A. Taga

Copyright (C) 2013 Naghi Saadatjou et al. This is an open access article distributed under the Creative Commons Attribution License, which permits unrestricted use, distribution, and reproduction in any medium, provided the original work is properly cited.

A simple and high sensitive preconcentration method based on micelle-mediated extraction followed by high performance liquid chromatography (LC-UV) was developed for preconcentration and determination of trace amounts of bisphenol A (BPA) in aqueous samples. The BPA was quantitatively extracted from aqueous samples in the presence of Triton X-114 as a nonionic surfactant and preconcentrated into the small volume (about $30 \mu \mathrm{L}$ ) of the surfactant-rich phase. Taguchi method, an orthogonal array design $\left(\mathrm{OA}_{16}\left(4^{5}\right)\right.$ ), was utilized to optimize the various factors affecting the micellar extraction of BPA. The maximum extraction efficiency of BPA was obtained at $\mathrm{pH} 3,0.2 \%(\mathrm{w} / \mathrm{v})$ Triton $\mathrm{X}-114$, and $0.25 \mathrm{~mol} \mathrm{~L}^{-1}$ sodium acetate. For the preconcentration, the solutions were incubated in a thermostatic water bath at $50^{\circ} \mathrm{C}$ for $7 \mathrm{~min}$. After centrifuge and separation of aqueous phase, the surfactant-rich phase was diluted with $100 \mu \mathrm{L}$ acetone and injected in the chromatographic system. Under the optimum conditions, preconcentration factor of 34.9 was achieved for extraction from $10 \mathrm{~mL}$ of sample solution and the relative standard deviation (RSD\%) of the method was lower than $6.6 \%$. The calibration curve was linear in the range of $0.5-150 \mu \mathrm{g} \mathrm{L}{ }^{-1}$ with reasonable linearity $\left(r^{2}>0.9987\right)$. The limit of detection (LOD) based on $S / N=3$ was $0.13 \mu \mathrm{g} \mathrm{L}^{-1}$ for $10 \mathrm{~mL}$ sample volumes. The limit of quantification (LOQ) based on $S / N=10$ was $0.43 \mu \mathrm{g} \mathrm{L}$ for $10 \mathrm{~mL}$ sample volumes. Finally, the applicability of the proposed method was evaluated by the extraction and determination of BPA in the real samples, and satisfactory results were obtained.

\section{Introduction}

The distribution and abundance of plastic particles in the environment have rapidly increased, and the adverse effects of chemicals that leach from the plastic debris on aquatic animals have been of great concern $[1,2]$. It is well known that 4,4-(1-methylethylidene) bisphenol or 2,2-(4,4dihydroxydiphenyl) propane (commonly named bisphenol A; BPA) has estrogenic activity $[3,4]$. BPA is a monomer widely used in the manufacture of epoxy and phenolic resins, as stabilizing material or antioxidant for numerous types of plastics including polyvinyl chloride $[5,6]$. It is also used in polycarbonates, polyacrylates, and corrosionresistant unsaturated polyester-styrene resins. BPA has been found to be widely distributed in the environment, because of highly production of plastics $[7,8]$. BPA is leached from lacquer-coated cans [4], polycarbonate flasks during autoclaving, and baby feeding bottles [9] due to the hydrolysis of the polymer during thermal treatment $[4,10,11]$. Therefore, highly reliable methods are required for the detection of trace amounts of BPA. Some sample preparation techniques such as liquid-liquid extraction (LLE) [12], dispersive liquid-liquid microextraction (DLLME) [13], solid-phase extraction [1416], and molecularly imprinted solid-phase extraction $[17,18]$ have been developed for the extraction of BPA from various matrices.

Micelle-mediated extraction is a simple and powerful extraction method that is based on the property of most nonionic surfactants in the aqueous solutions to form micelles and to separate into a surfactant-rich phase with a small volume. Any component present in the solution that interacts with the micellar aggregates can thus be extracted in the 
TABLE 1: Factors and levels for Taguchi orthogonal array design of proposed method (A-E are the respective codes for each factor).

\begin{tabular}{lccccc}
\hline \multirow{2}{*}{ Levels } & $\mathrm{A}(\mathrm{pH})$ & $\mathrm{B}($ surfactant $(\%))$ & $\mathrm{C}\left(\right.$ ionic strength $\left.\left(\mathrm{mol} \mathrm{L}^{-1}\right)\right)$ & $\mathrm{D}\left(\right.$ temperature $\left.\left({ }^{\circ} \mathrm{C}\right)\right)$ & E $($ organic solvent volume $(\mu \mathrm{L}))$ \\
\hline 1 & 3 & 0.05 & 0.01 & 30 & 50 \\
2 & 4 & 0.1 & 0.1 & 40 & 75 \\
3 & 5 & 0.2 & 0.25 & 50 & 100 \\
4 & 6 & 0.3 & 0.5 & 60 & 125 \\
\hline
\end{tabular}

surfactant-rich phase. Small volume of the surfactant-rich phase and its compatibility with hydroorganic mobile phases allow the extraction and preconcentration of organic compounds prior to high-performance liquid chromatography (LC) [19] and capillary electrophoresis (CE) [20]. For LC, the viscosity of the surfactant-rich phase and its adsorption on the analytical columns can be resulted in the broad overlapping peaks when UV detection was employed. A lot of experimental studies were devoted to resolving this problem; one of them was decreasing the viscosity of the surfactantrich phase by use of organic solvent before its introduction to LC. However, micelle-mediated extraction can easily be adapted for LC. It improves the detection limit and selectivity of determinations. In the present study, the applicability of the micellar extraction prior to LC-UV for the preconcentration and determination of trace amounts of BPA in aqueous samples was investigated using orthogonal array experimental design.

\section{Experimental}

2.1. Reagents and Materials. All chemicals used were of analytical reagent grade and were prepared from Merck (Darmstadt, Germany) and Fluka companies (Chemie AG, Switzerland). LC-grade solvents (water, methanol, and acetonitrile) were used throughout the experiments and were obtained from Merck. All solutions were prepared with doubly distilled water. A stock standard solution of BPA at a concentration of $1000 \mathrm{mg} \mathrm{L}^{-1}$ was prepared in methanol. This standard solution was diluted with distilled water to prepare stock solutions with the concentration of 5,10 , and $50 \mathrm{mg} \mathrm{L}^{-1}$ of BPA. The non-ionic surfactant, Triton X-114 from Fluka, was used without further purification. Nitric acid $\left(1.0 \mathrm{~mol} \mathrm{~L}^{-1}\right)$ and sodium hydroxide $\left(1.0 \mathrm{~mol} \mathrm{~L}^{-1}\right)$ were used to adjust the $\mathrm{pH}$ of solutions.

2.2. Apparatus. Chromatographic separations were carried out on a Knauer LC equipped with a K-1001 LC pump (Germany) and a K-2600 UV-Vis detector. Separations were carried out on a Zorbax Extend $\mathrm{C}_{18}$ column $(250 \mathrm{~mm} \times$ $4.6 \mathrm{~mm}$ i.d., $5 \mu \mathrm{m}$ particle diameter). A mixture of deionized water and acetonitrile $(55: 45)$ at a constant flow rate of $1.0 \mathrm{~mL} \mathrm{~min}{ }^{-1}$ was used as the mobile phase in isocratic mode. The injection volume was $20 \mu \mathrm{L}$ for all the solutions, and the detection was performed at the wavelength of $224 \mathrm{~nm}$. A model 3305 digital Jenway $\mathrm{pH}$ meter equipped with a combined glass-calomel electrode was used for the $\mathrm{pH}$ adjustments. A centrifuge (Model H-108 N, Kokusan, Democrartic
People's Republic of Korea) was applied to accelerate the separation of surfactant-rich phase from aqueous solution.

2.3. Extraction Procedure. For the cloud point extraction, aliquots of the solution containing BPA $(10 \mathrm{~mL})$ were adjusted to the appropriate ionic strength and $\mathrm{pH}$ (sodium acetate: $0.25 \mathrm{~mol} \mathrm{~L}^{-1}, \mathrm{pH} 3.0$ ). Triton X-114 at $0.2 \%(\mathrm{w} / \mathrm{v})$ concentration was added to solutions and the solutions were kept at $50^{\circ} \mathrm{C}$ (the temperature above the cloud point temperature of the system) for $7 \mathrm{~min}$ in the thermostatic water bath to become cloudy. Since Triton X-114 is denser than water, the surfactant-rich phase typically settled through the aqueous phase. In order to accelerate the phase separation, the turbid solutions were centrifuged for $8 \mathrm{~min}$ at $3000 \mathrm{rpm}$. After that, the tubes were cooled in an ice bath for $5 \mathrm{~min}$ to reach a denser surfactant-rich phase that could facilitate the separation of aqueous phase by means of pipette. After the separation of aqueous phase, $100 \mu \mathrm{L}$ of pure acetone was added to the surfactant-rich phase to decrease the viscosity of surfactantrich phase for further measurement by LC-UV.

\section{Results and Discussion}

3.1. Method Development. In the proposed procedure, to achieve maximum extraction efficiency, various parameters affecting the extraction of BPA were studied using the Taguchi orthogonal array design (OAD). Taguchi method is a type of fractional factorial design in which orthogonal array is used to assign the selected factors to a serial of experimental combinations [21]. The results of the orthogonal array design experiments can be treated by the analysis of variance (ANOVA) and/or the direct observation analysis. In ANOVA, the effects of different factors on the response function can be evaluated by computing $F$-ratio (variances ratio) and percent contribution (PC) values for each factor [22, 23]. All optimization experiments were done at $100 \mu \mathrm{g} \mathrm{L}^{-1}$ of BPA, and Falcon tubes with $15 \mathrm{~mL}$ volumes were used for optimization.

3.2. Experimental Design and Data Analysis. In this study, the effect of five experimental factors including solution $\mathrm{pH}$ and temperature, surfactant concentration, ionic strength, and organic solvent volume (acetone) on the micelle-mediated extraction of BPA was studied using Taguchi's $\mathrm{OA}_{16}$ design. The used levels (four levels) of the main factors (A-E) and the $\mathrm{OA}_{16}\left(4^{5}\right)$ matrix employed to assign the considered factors are shown in Tables 1 and 2 , respectively. 
TABLE 2: $\mathrm{OA}_{16}\left(4^{5}\right)$ experimental design for the optimization of CPE of BPA.

\begin{tabular}{lccccc}
\hline $\begin{array}{l}\text { Trial } \\
\text { no. }\end{array}$ & $\mathrm{pH}$ & $\begin{array}{c}\% \\
\text { Surfactant }\end{array}$ & $\begin{array}{c}\text { Ionic } \\
\text { strength } \\
\left(\mathrm{mol} \mathrm{L}^{-1}\right)\end{array}$ & $\begin{array}{c}\text { Temperature } \\
\left({ }^{\circ} \mathrm{C}\right)\end{array}$ & $\begin{array}{c}\text { Organic } \\
\text { solvent } \\
\text { volume }(\mu \mathrm{L})\end{array}$ \\
\hline 1 & 6 & 0.3 & 0.01 & 50 & 75 \\
2 & 5 & 0.1 & 0.5 & 50 & 50 \\
3 & 4 & 0.05 & 0.1 & 50 & 125 \\
4 & 3 & 0.3 & 0.5 & 60 & 125 \\
5 & 3 & 0.1 & 0.1 & 40 & 75 \\
6 & 5 & 0.3 & 0.1 & 30 & 100 \\
7 & 3 & 0.2 & 0.25 & 50 & 100 \\
8 & 5 & 0.05 & 0.25 & 60 & 75 \\
9 & 4 & 0.2 & 0.5 & 30 & 75 \\
10 & 5 & 0.2 & 0.01 & 40 & 125 \\
11 & 6 & 0.1 & 0.25 & 30 & 125 \\
12 & 3 & 0.05 & 0.01 & 30 & 50 \\
13 & 4 & 0.3 & 0.25 & 40 & 50 \\
14 & 6 & 0.05 & 0.5 & 40 & 100 \\
15 & 6 & 0.2 & 0.1 & 60 & 50 \\
16 & 4 & 0.1 & 0.01 & 60 & 100 \\
\hline
\end{tabular}

The designing of the table was done via experimental design 7.0 software. For increasing the precision of the optimization process, each trial was repeated twice $(n=32)$. The sequence, in which the experiments were carried out, was randomized to avoid any personal or subjective bias. ANOVA was used to assess the OAD results. For ANOVA calculations, peak area of BPA in the chromatogram was used and the results of the sums of squares (SS) for different variables were calculated.

The mean values of the four levels of each factor revealed how the extraction efficiency changes with variation of the level of each factor. Figure 1 shows the mean absorbance as a function of the levels of the studied factors.

The ANOVA results (Table 3 ) showed that the most important factor contributing to the extraction efficiency was acetone volume $(44.21 \%)$. The results also showed that $\mathrm{pH}$ had low effect on the extraction.

\subsection{Study of Micelle-Mediated Extraction}

3.3.1. Influence of $p H$. BPA with $p K_{a}$ value in the range of 9.6-10.2 should mainly exist as a neutral compound at $\mathrm{pHs}$ below 9.0 and it can be extracted to hydrophobic core of micellar aggregates. At pHs higher than 10, BPA exists as an ionic form that has extremely water solubility. Hence, the extraction of BPA was performed at acidic $\mathrm{pH}$. To investigate the effect of $\mathrm{pH}$ on the extraction of $\mathrm{BPA}, \mathrm{pH}$ of the samples was adjusted in the range of 3.0-6.0 using the sodium acetate $\left(0.25 \mathrm{~mol} \mathrm{~L}^{-1}\right)$ with addition of $\mathrm{NaOH}\left(1.0 \mathrm{~mol} \mathrm{~L}^{-1}\right)$ or $\mathrm{HNO}_{3}$ $\left(1.0 \mathrm{~mol} \mathrm{~L}^{-1}\right)$, according to the experimental design (Figure 1). The results showed that the maximum extraction efficiency of BPA was obtained at $\mathrm{pH} 3$.

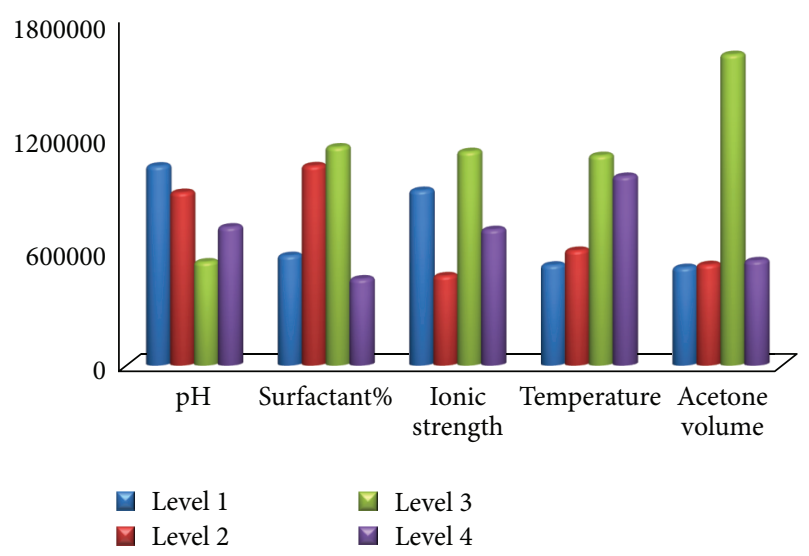

FIGURE 1: The response graph illustrating the variation of the mean area peak values plotted against various extraction parameters. $\mathrm{pH}$ (level $1=3.0$, level $2=4.0$, level $3=5.0$, level $4=6.0$ ). Surfactant $(\%)$ (level $1=0.05$, level $2=0.1$, level $3=0.2$, level $4=0.3$ ). Ionic strength $\left(\mathrm{mol} \mathrm{L}^{-1}\right)($ level $1=0.01$, level $2=0.1$, level $3=0.25$, level $4=0.5)$. Temperature $\left({ }^{\circ} \mathrm{C}\right)($ level $1=30$, level $2=40$, level $3=50$, level $4=60)$. Acetone volume $(\mu \mathrm{L})($ level $1=50$, level $2=75$, level $3=100$, level 4 $=125)$.

3.3.2. Influence of Triton $X-114$ Concentration. In CPE, the theoretical preconcentration factors depend on the volume of the surfactant-rich phase, which at the same time varies with the surfactant concentration in the solution [29]. In the present study, Triton X-114 as a non-ionic surfactant was chosen for its low cloud-point temperature, low toxicological properties, and high density $[30,31]$. The effect of the surfactant concentration on the extraction efficiency was studied in the range of $0.05-0.3 \%(\mathrm{w} / \mathrm{v})$. According to Figure 1 , at $0.2 \%$ $(\mathrm{w} / \mathrm{v})$ of Triton X-114, more extraction was occurred. At lower concentrations of the surfactant, the extraction efficiency was low probably due to inadequacy of the assemblies to entrap the BPA quantitatively. At higher concentrations, the signal's intensity decreased probably due to increase in the viscosity and the volume of the surfactant phase. To obtain maximum preconcentration factor, $0.2 \%(\mathrm{w} / \mathrm{v})$ of Triton $\mathrm{X}$ 114 was selected for further experiments.

3.3.3. Influence of Ionic Strength. The addition of salt to solution can influence the phase separation process. To study the influence of the ionic strength on the extraction performance, the concentration of sodium acetate was changed in the range of $0.01-0.5 \mathrm{~mol} \mathrm{~L}^{-1}$. The results showed that the addition of the sodium acetate facilitates the phase separation since it increases the density of the aqueous phase [32]. With the increase of the salt concentration, the micellar size and the aggregation number are increased [33]. According to Figure 1, the extraction at $0.25 \mathrm{~mol} \mathrm{~L}^{-1}$ sodium acetate gives the best results. At very high concentrations of sodium acetate the surfactant-rich phase was located on the surface of the solution, which makes it more difficult to separate the extraction solvent.

3.3.4. Influence of Equilibrium Temperature. It was desirable to employ the lowest possible equilibration temperature, 
TABLE 3: ANOVA results for experimental responses in the $\mathrm{OA}_{16}\left(4^{5}\right)$ matrix.

\begin{tabular}{lccccr}
\hline Factor & DOF $^{\mathrm{a}}$ & Sum of squares & Variance & F-ratio $^{\text {b }}$ & Pure sum of squares $^{\text {\% PC }}$ \\
\hline $\mathrm{pH}(\mathrm{A})$ & 3 & $1.1107 \times 10^{12}$ & $2.7768 \times 10^{11}$ & 0.21 & $9.283 \times 10^{11}$ \\
\% surfactant (B) & 3 & $2.70846 \times 10^{12}$ & $6.77115 \times 10^{11}$ & 0.514 & $2.526 \times 10^{12}$ \\
Ionic strength (C) & 3 & $1.80809 \times 10^{12}$ & $4.52022 \times 10^{11}$ & 0.343 & $1.626 \times 10^{12}$ \\
Temperature (D) & 3 & $1.86311 \times 10^{12}$ & $4.65777 \times 10^{11}$ & 0.353 & $1.681 \times 10^{12}$ \\
Organic solvent volume $(\mu \mathrm{L})$ & 3 & $7.03123 \times 10^{12}$ & $1.75781 \times 10^{11}$ & 1.333 & 10.85 \\
Error & 16 & $0.729 \times 10^{11}$ & $6.08062 \times 10^{10}$ & & 44.21 \\
\hline Total & 31 & $1.54945 \times 10^{13}$ & & & 12.16 \\
\hline
\end{tabular}

${ }^{\mathrm{a}}$ Degrees of freedom. ${ }^{\mathrm{b}} \mathrm{F}$, critical value is $3.24(P<0.05) .{ }^{\mathrm{c}}$ Percent of contribution.

which compromises completion of the reaction and efficient separation of the phases.

For Triton X-114, an increase in the cloud point temperature leads to a slight decrease in the volume of the surfactantrich phase. This can be interpreted in terms of the fact that as temperature increases, hydrogen bonds are disrupted and dehydration occurs. Thus, by increasing of temperature, the amount of water in the surfactant-rich phase and consequently the volume of the surfactant-rich phase decrease [34]. The greatest preconcentration can be obtained when the extraction is conducted at the temperatures well above the cloud point temperature of the surfactant. According to Figure 1, the optimum equilibration temperature was found to be $50^{\circ} \mathrm{C}$.

3.3.5. Influence of Organic Solvent Volume. After extraction and separation of the surfactant-rich phase from aqueous phase, it is necessary to decrease its viscosity before injection to LC. Acetone, acetonitrile, and methanol were studied as an organic solvents. In order to investigate the effect of solvent type on extraction performance a series of extracted samples of BPA $\left(100 \mu \mathrm{g} \mathrm{L}^{-1}\right)$ were prepared and $50 \mu \mathrm{L}$ of each solvent was added into the surfactant-rich phase. Acetone has the best chromatographic results in comparison with other solvent. After selection of acetone as organic solvent, the effect of its volume on the peak area of BPA was investigated in the range of $50-125 \mu \mathrm{L}$. According to Figure $1,100 \mu \mathrm{L}$ of acetone showed the best results. The viscosity of surfactant-rich phase decreased by increasing of the acetone volume. At higher acetone volumes (above $100 \mu \mathrm{L}$ ), the preconcentration factor decreased because of increase in the volume of extractant.

3.4. Evaluation of Method Performance. The quantitative parameters of the proposed method were calculated under the optimized conditions $(\mathrm{pH} 3,0.2 \%(\mathrm{w} / \mathrm{v})$ surfactant, $0.25 \mathrm{~mol} \mathrm{~L}^{-1}$ ionic strength, temperature $50^{\circ} \mathrm{C}$, and $100 \mu \mathrm{L}$ acetone). The calibration curve was obtained by preconcentration of BPA in $10 \mathrm{~mL}$ of spiked standard solutions under the optimum conditions. The calibration line exhibited a good linearity over the concentration range of $0.5-150 \mu \mathrm{g} \mathrm{L}^{-1}$ with correlation coefficient better than 0.9987 . The limit of detection (LOD), calculated as the concentration equivalent to three times of the blank standard deviation (for ten replicates) divided into the slope of calibration curve, was $0.13 \mu \mathrm{g} \mathrm{L} \mathrm{L}^{-1}$. The limit of quantification (LOQ) based on $S / N=10$ was $0.43 \mu \mathrm{g} \mathrm{L}^{-1}$ for $10 \mathrm{~mL}$ sample volumes. The preconcentration
TABLE 4: Comparison of the characteristic data between recently published extraction methods and the developed method.

\begin{tabular}{lccccc}
\hline Methods & $\begin{array}{c}\mathrm{LOD} \\
\left(\mu \mathrm{g} \mathrm{L}^{-1}\right)\end{array}$ & $\begin{array}{c}\mathrm{LR}^{\mathrm{a}} \\
\left(\mu \mathrm{g} \mathrm{L}^{-1}\right)\end{array}$ & $\begin{array}{c}\mathrm{RSD} \\
(\%)\end{array}$ & $\begin{array}{c}\mathrm{SV}^{\mathrm{b}} \\
(\mathrm{mL})\end{array}$ & Reference \\
\hline LPME $^{\mathrm{c}}$-GC-MS & 5.0 & $1-1000$ & 15 & 10 & {$[24]$} \\
SBSE $^{\mathrm{d}}$-GC-MS & 0.5 & $2-100$ & $<10$ & 2 & {$[25]$} \\
SPME $^{\mathrm{e}}$-LC & 3.25 & $10-500$ & 4.4 & 10 & {$[26]$} \\
ELISA $^{\mathrm{f}}$ & 0.3 & $0.3-100$ & - & 10 & {$[27]$} \\
ELISA $^{\text {DLLME }}$ & 0.1 & $1-10000$ & - & 10 & {$[28]$} \\
CPE-LC $^{\mathrm{g}}$ & 0.07 & $0.5-100$ & 6 & 10 & {$[13]$} \\
& 0.13 & $0.5-150$ & 6.6 & 10 & $\begin{array}{c}\text { Proposed } \\
\text { method }\end{array}$ \\
\hline
\end{tabular}

${ }^{\mathrm{a}}$ Linear range. ${ }^{\mathrm{b}}$ Sample volume. ${ }^{\mathrm{c}}$ Liquid phase microextraction. ${ }^{\mathrm{d}}$ Stir bar sorptive extraction. ${ }^{\mathrm{e}}$ Solid phase microextraction. ${ }^{\mathrm{f}}$ Enzyme-linked immunosorbent assay. ${ }^{\mathrm{g}}$ Dispersive liquid-liquid microextraction.

factor was calculated as the ratio of concentration of analyte in the surfactant-rich phase to its initial concentration in aqueous solution $\left(100 \mu \mathrm{g} \mathrm{L}^{-1}\right)$. The preconcentration factor was 34.9 for $10 \mathrm{~mL}$ sample. The relative standard deviation (RSD\%) resulted from four replicate extractions of BPA from $10 \mathrm{~mL}$ solution $\left(100 \mu \mathrm{g} \mathrm{L}^{-1}\right)$ was lower than $6.6 \%$.

A comparison between the figures of merit of the proposed method and some of the recently published methods for extraction and determination of BPA is summarized in Table 4 .

The extraction method applied in the present work has some advantages in comparison with the other extraction methods including low consumption of organic solvents and reagents, ease of operation, simplicity, minimum carry over, and cross-contamination as well as producing a clean extracting phase for the analysis.

3.5. Analysis of Real Samples. The applicability of the proposed method to real samples was studied by analyzing the lagoon water collected from Bojagh lagoon (Kiashahr, Gilan, Iran) and the leachate (BPA) from the solution of the baby feeding bottle and transfusion distilled water (preservation in plastic bottle). The leachate of baby feeding bottle was collected from the containers filled with $150 \mathrm{~mL}$ of boiling water. A $150 \mathrm{~mL}$ of boiling water $\left(100^{\circ} \mathrm{C}\right)$ was transferred into a commercially available baby feeding bottle, which was tightly capped and kept in an oven at $95^{\circ} \mathrm{C}$ for $30 \mathrm{~min}$ and 


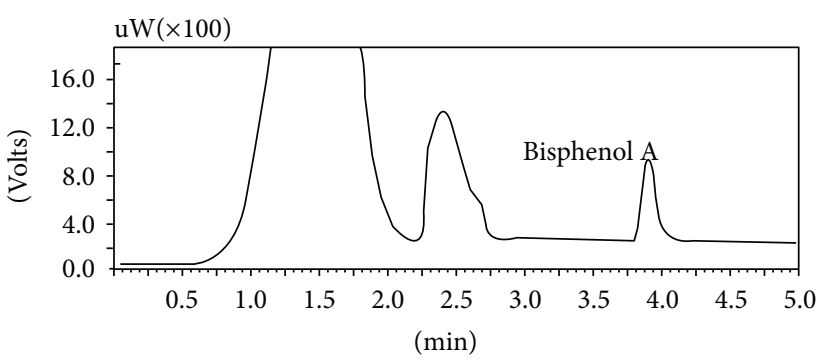

(a)

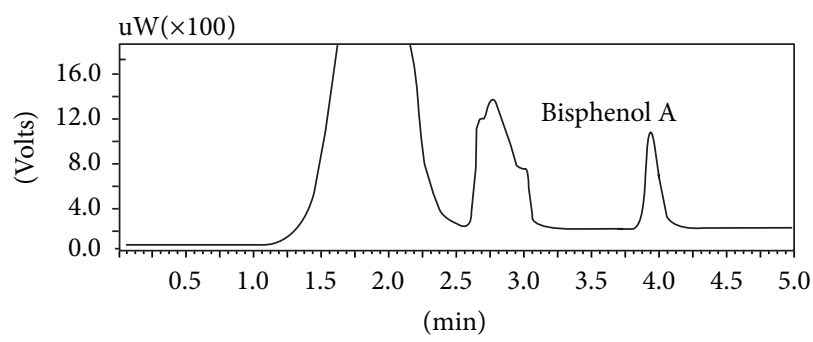

(c)

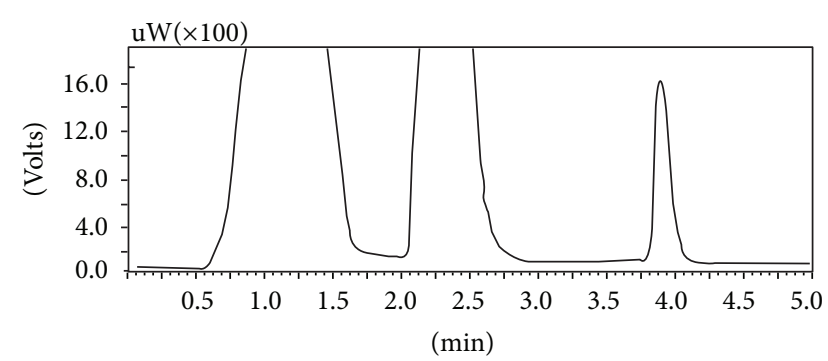

(b)

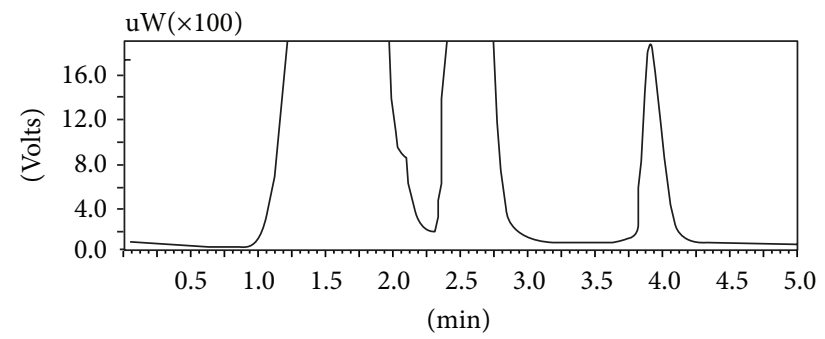

(d)

Figure 2: LC chromatograms of BPA leached BPA from baby feeding bottle (a) nonspiked and without being kept in oven, (b) spiked $\left(10 \mu \mathrm{g} \mathrm{L}^{-1}\right)$ and without being kept in oven, (c) nonspiked and kept in oven (at $95^{\circ} \mathrm{C}$ for $30 \mathrm{~min}$ ), and (d) spiked (10 $\left.\mu \mathrm{g} \mathrm{L}{ }^{-1}\right)$ and kept in oven.

TABLE 5: Analytical results for determination of BPA in real ware samples.

\begin{tabular}{|c|c|c|c|}
\hline \multirow{2}{*}{ Sample } & \multicolumn{3}{|c|}{ Concentration (mean, $n=3)\left(\mu \mathrm{g} \mathrm{mL}^{-1}\right)$} \\
\hline & BPA added & BPA found & Recovery (\%) \\
\hline \multirow{2}{*}{$\mathrm{S}_{1}$} & 0.0 & $1.16 \pm 0.22$ & \multirow{2}{*}{103} \\
\hline & 10.0 & $11.53 \pm 0.66$ & \\
\hline \multirow{2}{*}{$\mathrm{S}_{2}$} & 0.0 & $1.99 \pm 0.27$ & \multirow{2}{*}{98} \\
\hline & 10.0 & $11.84 \pm 0.35$ & \\
\hline \multirow{2}{*}{$\mathrm{S}_{3}$} & 0.0 & $4.50 \pm 0.65$ & \multirow{2}{*}{97} \\
\hline & 10.0 & $14.14 \pm 0.71$ & \\
\hline \multirow{2}{*}{$\mathrm{S}_{4}$} & 0.0 & $2.39 \pm 0.27$ & \multirow{2}{*}{97} \\
\hline & 10.0 & $12.05 \pm 0.3$ & \\
\hline
\end{tabular}

$\mathrm{S}_{1}$ : transfusion distilled water (preservation in plastic bottle).

$\mathrm{S}_{2}$ : leachate from baby feeding bottle.

$\mathrm{S}_{3}$ : leachate from baby feeding bottle kept in oven $\left(95^{\circ} \mathrm{C}-30 \mathrm{~min}\right)$.

$\mathrm{S}_{4}$ : lagoon water collected from Bojagh lagoon (Gilan, Iran).

cooled to room temperature. Another leachate sample from baby feeding bottle was tested without thermal processing. Figure 2 shows the chromatograms obtained for the leachate samples from baby feeding bottle kept in $95^{\circ} \mathrm{C}$ and without thermal processing.

Results (Table 5) showed that BPA leached from baby feeding bottle after thermal processing in oven was more than ones without any thermal processing.

\section{Conclusion}

The use of micellar systems as an alternative to other methods of separation and preconcentration offers several advantages including experimental convenience, safety and being an inexpensive method. Also, in this method, the consumption of organic solvent is low. In the present study, the results of ANOVA showed that the $\mathrm{pH}$ has low significant effect on the extraction efficiency. The proposed method gives low limit of detection as well as good RSD and linearity that results detection of low concentration of BPA in samples.

\section{References}

[1] C. S. Wong, D. R. Green, and W. J. Cretney, "Quantitative tar and plastic waste distributions in the Pacific Ocean," Nature, vol. 247, no. 5435, pp. 30-32, 1974.

[2] J. B. Colton, F. D. Knapp, and B. R. Burns, "Plastic particles in surface waters of the Northwestern Atlantic," Science, vol. 185, no. 4150, pp. 491-497, 1974.

[3] A. V. Krishnan, P. Stathis, S. F. Permuth, L. Tokes, and D. Feldman, "Bisphenol-A: an estrogenic substance is released from polycarbonate flasks during autoclaving," Endocrinology, vol. 132, no. 6, pp. 2279-2286, 1993.

[4] J. A. Brotons, M. F. Olea-Serrano, M. Villalobos, V. Pedraza, and N. Olea, "Xenoestrogens released from lacquer coatings in food cans," Environmental Health Perspectives, vol. 103, no. 6, pp. 608-612, 1995.

[5] M. Ash and I. Ash, Handbook of Plastic and Rubber Additives, Gower, Hampshire, UK, 1995.

[6] C. M. Chang, C. C. Chou, and M. R. Lee, "Determining leaching of bisphenol A from plastic containers by solid-phase microextraction and gas chromatography-mass spectrometry," Analytica Chimica Acta, vol. 539, no. 1-2, pp. 41-47, 2005.

[7] Environmental agency of Japan. Chemicals in the environment, 1997.

[8] T. Yamamoto, A. Yasuhara, H. Shiraishi, and O. Nakasugi, "Bisphenol A in hazardous waste landfill leachates," Chemosphere, vol. 42, no. 4, pp. 415-418, 2001. 
[9] J. E. Biles, T. P. McNeal, T. H. Begley, and H. C. Hollifield, "Determination of bisphenol-A in reusable polycarbonate foodcontact plastics and migration to food-simulating liquids," Journal of Agricultural and Food Chemistry, vol. 45, no. 9, pp. 3541-3544, 1997.

[10] P. Parez, R. Pulgar, F. Olea-Serrano et al., "The estrogenicity of bisphenol A-related diphenylalkanes with various substituents at the central carbon and the hydroxy groups," Environmental Health Perspectives, vol. 106, no. 3, pp. 167-174, 1998.

[11] S. C. Nagel, F. S. Vom Saal, K. A. Thayer, M. G. Dhar, M. Boechler, and W. V. Welshons, "Relative binding affinity-serum modified access (RBA-SMA) assay predicts the relative in vivo bioactivity of the xenoestrogens bisphenol A and octylphenol," Environmental Health Perspectives, vol. 105, no. 1, pp. 70-76, 1997.

[12] J. L. Vílchez, A. Zafra, A. González-Casado, E. Hontoria, and M. Del Olmo, "Determination of trace amounts of bisphenol F, bisphenol A and their diglycidyl ethers in wastewater by gas chromatography-mass spectrometry," Analytica Chimica Acta, vol. 431, no. 1, pp. 31-40, 2001.

[13] M. Rezaee, Y. Yamini, S. Shariati, A. Esrafili, and M. Shamsipur, "Dispersive liquid-liquid microextraction combined with highperformance liquid chromatography-UV detection as a very simple, rapid and sensitive method for the determination of bisphenol A in water samples," Journal of Chromatography A, vol. 1216, no. 9, pp. 1511-1514, 2009.

[14] U. Bolz, W. Körner, and H. Hagenmaier, "Development and validation of a GC/MS method for determination of phenolic xenoestrogens in aquatic samples," Chemosphere, vol. 40, no. 911, pp. 929-935, 2000.

[15] S. N. Pedersen and C. Lindholst, "Quantification of the xenoestrogens 4-tert.-octylphenol and bisphenol $\mathrm{A}$ in water and in fish tissue based on microwave assisted extraction, solidphase extraction and liquid chromatography-mass spectrometry," Journal of Chromatography A, vol. 864, no. 1, pp. 17-24, 1999.

[16] H. G. J. Mol, S. Sunarto, and O. M. Steijger, "Determination of endocrine disruptors in water after derivatization with $\mathrm{N}$-methyl-N-(tert-butyldimethyltrifluoroacetamide) using gas chromatography with mass spectrometric detection," Journal of Chromatography A, vol. 879, no. 1, pp. 97-112, 2000.

[17] M. Kawaguchi, Y. Hayatsu, H. Nakata et al., "Molecularly imprinted solid phase extraction using stable isotope labeled compounds as template and liquid chromatography-mass spectrometry for trace analysis of bisphenol A in water sample," Analytica Chimica Acta, vol. 539, no. 1-2, pp. 83-89, 2005.

[18] B. San Vicente, F. Navarro Villoslada, and M. C. Moreno-Bondi, "Continuous solid-phase extraction and preconcentration of bisphenol a in aqueous samples using molecularly imprinted columns," Analytical and Bioanalytical Chemistry, vol. 380, no. 1, pp. 115-122, 2004.

[19] A. Eiguren Fernández, Z. Sosa Ferrera, and J. J. Santana Rodríguez, "Application of cloud-point methodology to the determination of polychlorinated dibenzofurans in sea water by high-performance liquid chromatography," Analyst, vol. 124, no. 4, pp. 487-491, 1999.

[20] R. Carabias-Martinez, E. Rodriguez-Gonzalo, J. DominguezAlvarez, and J. Hernández-Méndez, "Cloud point extraction as a preconcentration step prior to capillary electrophoresis," Analytical Chemistry, vol. 71, no. 13, pp. 2468-2474, 1999.

[21] A. Saleh, Y. Yamini, M. Faraji, S. Shariati, and M. Rezaee, "Hollow fiber liquid phase microextraction followed by high performance liquid chromatography for determination of ultratrace levels of $\mathrm{Se}(\mathrm{IV})$ after derivatization in urine, plasma and natural water samples," Journal of Chromatography B, vol. 877, no. 18-19, pp. 1758-1764, 2009.

[22] R. K. Roy, A Primer on Taguchi Method, Van Nostrand Reinhold, New York, NY, USA, 1990.

[23] G. Zhu and H. Ju, "Determination of naproxen with solid substrate room temperature phosphorimetry based on an orthogonal array design," Analytica Chimica Acta, vol. 506, no. 2, pp. 177-181, 2004.

[24] S. C. Cunha, C. Almeida, E. Mendes, and J. O. Fernandes, "Simultaneous determination of bisphenol A and bisphenol B in beverages and powdered infant formula by dispersive liquidliquid micro-extraction and heart-cutting multidimensional gas chromatography-mass spectrometry," Food Additives and Contaminants Part A, vol. 28, no. 4, pp. 513-526, 2011.

[25] M. Kawaguchi, K. Inoue, M. Yoshimura et al., "Determination of bisphenol $\mathrm{A}$ in river water and body fluid samples by stir bar sorptive extraction with in situ derivatization and thermal desorption-gas chromatography-mass spectrometry," Journal of Chromatography B, vol. 805, no. 1, pp. 41-48, 2004.

[26] L. Deng, Y. X. Liu, P. Y. Chen, L. Wang, and N. S. Deng, "Determination of trace bisphenol A in leachate by solid phase microextraction coupled with high performance liquid chromatography," Analytical Letters, vol. 39, no. 2, pp. 395-404, 2006.

[27] H. Ohkuma, K. Abe, M. Ito, A. Kokado, A. Kambegawa, and M. Maeda, "Development of a highly sensitive enzyme-linked immunosorbent assay for bisphenol A in serum," Analyst, vol. 127, no. 1, pp. 93-97, 2002.

[28] M. P. Zhao, Y. Z. Li, Z. Q. Guo, X. X. Zhang, and W. B. Chang, "A new competitive enzyme-linked immunosorbent assay (ELISA) for determination of estrogenic bisphenols," Talanta, vol. 57, no. 6, pp. 1205-1210, 2002.

[29] B. Delgado, V. Pino, J. H. Ayala, V. González, and A. M. Afonso, "Nonionic surfactant mixtures: a new cloud-point extraction approach for the determination of PAHs in seawater using HPLC with fluorimetric detection," Analytica Chimica Acta, vol. 518, no. 1-2, pp. 165-172, 2004.

[30] M. Ghambarian, Y. Yamini, A. Saleh, S. Shariati, and N. Yazdanfar, "Taguchi $\mathrm{OA}_{16}$ orthogonal array design for the optimization of cloud point extraction for selenium determination in environmental and biological samples by tungsten-modified tube electrothermal atomic absorption spectrometry," Talanta, vol. 78, no. 3, pp. 970-976, 2009.

[31] F. Shemirani, M. Baghdadi, M. Ramezani, and M. R. Jamali, "Determination of ultra trace amounts of bismuth in biological and water samples by electrothermal atomic absorption spectrometry (ET-AAS) after cloud point extraction," Analytica Chimica Acta, vol. 534, no. 1, pp. 163-169, 2005.

[32] R. Carabias-Martínez, E. Rodriguez-Gonzalo, B. MorenoCordero, J. L. Pérez-Pavón, C. Garcia-Pinto, and E. Fernandez Laespada, "Surfactant cloud point extraction and preconcentration of organic compounds prior to chromatography and capillary electrophoresis," Journal of Chromatography A, vol. 902, no. 1, pp. 251-265, 2000.

[33] B. Fröschl, G. Stangl, and R. Niessner, "Combination of micellar extraction and GC-ECD for the determination of polychlorinated biphenyls (PCBs) in water,' Fresenius' Journal of Analytical Chemistry, vol. 357, no. 6, pp. 743-746, 1997.

[34] R. P. Frankewich and W. L. Hinze, "Evaluation and optimization of the factors affecting nonionic surfactant-mediated phase separations," Analytical Chemistry, vol. 66, no. 7, pp. 944-954, 1994. 

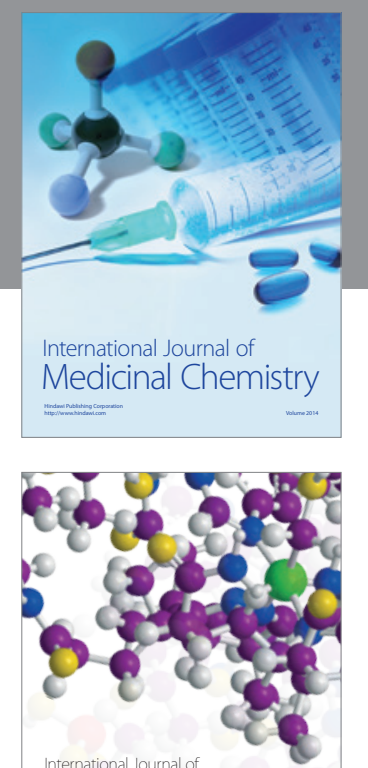

\section{Carbohydrate} Chemistry

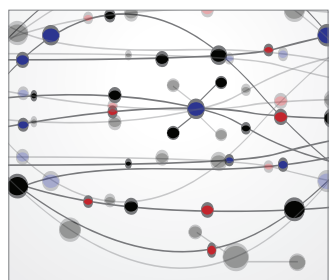

The Scientific World Journal
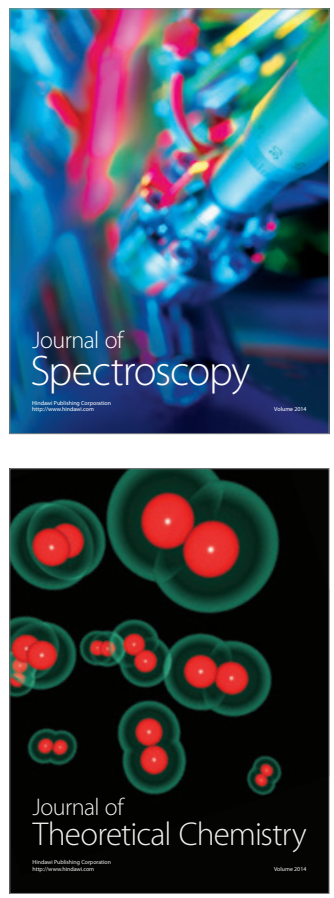
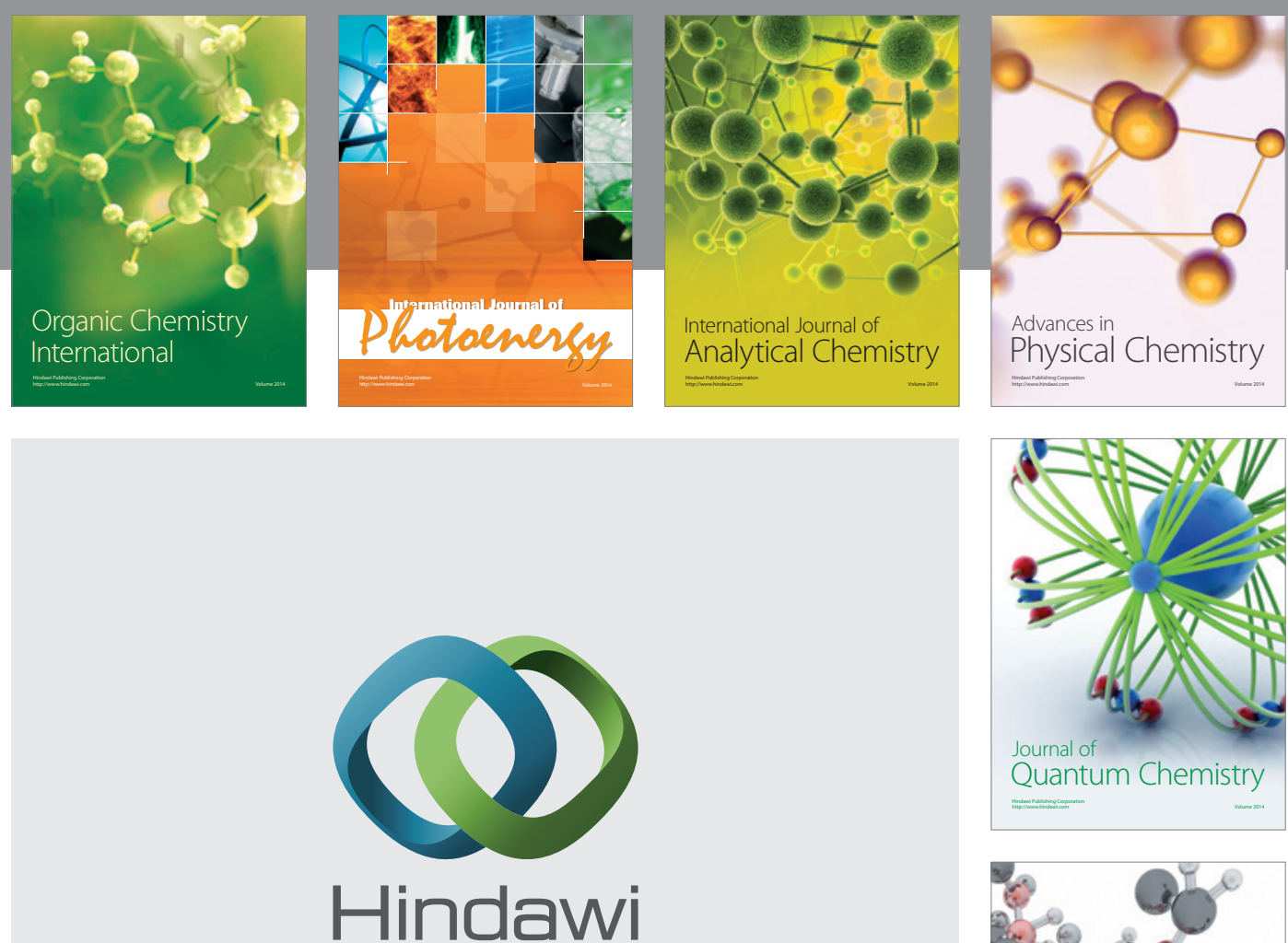

Submit your manuscripts at

http://www.hindawi.com

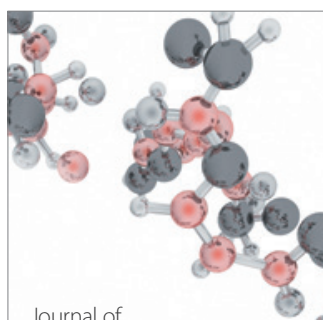

Analytical Methods

in Chemistry

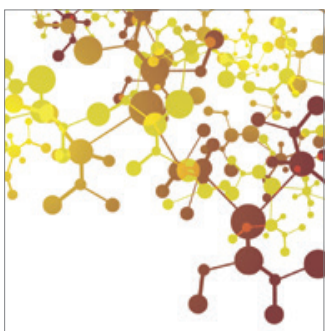

Journal of

Applied Chemistry

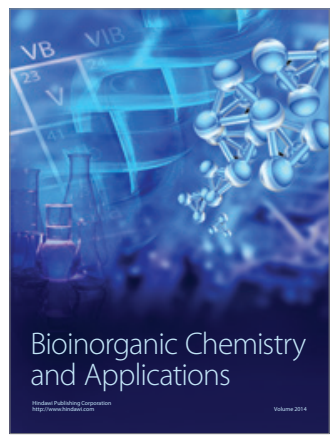

Inorganic Chemistry
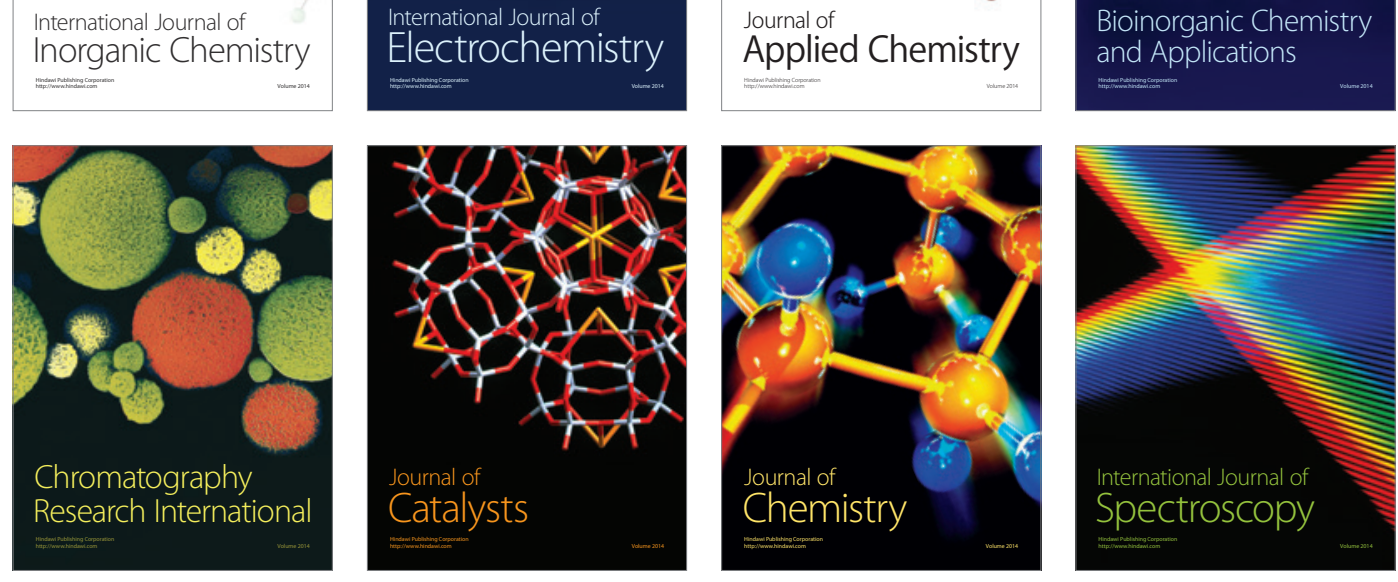